\title{
TITLE: HEMODYNAMIC EFFECTS OF RETROPERITONEAL LAPAROSCOPY IN CHILDREN
}

Cengiz Karsli MD, Mirko Dolci MD, Igor Luginbuehl MD, Walid Farhat MD, Bruno Bissonnette MD

University of Toronto, Department of Anesthesia, Sick Kids, 555 University Avenue, Toronto, Ontario, M5G 1X8

INTRODUCTION: Retroperitoneal laparoscopy is a technique which is being used with increasing regularity.(1) Intraperitoneal laparoscopy has been shown to have no effect on cardiac index, blood pressure or heart rate in children.(2) This study examines the systemic hemodynamic effects of retroperitoneal $\mathrm{CO}_{2}$ insufflation in children.

METHODS: With REB approval and written parental consent pediatric patients undergoing laparoscopic partial or total nephrectomy were enrolled. A standardized anesthetic technique of isoflurane $1 \mathrm{MAC}$ and remifentanil $0.2 \mu \mathrm{g} / \mathrm{kg} / \mathrm{min}$ was used. Parameters measured included peak airway pressure, end-tidal $\mathrm{CO}_{2}$, heart rate and mean arterial blood pressure. Data was collected before, during and after $12 \mathrm{mmHg}$ of pneumoperitoneum, at regular 1-2 minute intervals. Within group analysis was performed using repeated measures ANOVA and values at different points of time were compared using paired t-test. $P<0.05$ was considered significant.

RESULTS: Twelve participants with a mean age of $6.5 \pm 4.8 \mathrm{yr}$ and weight of $23.9 \pm$ $13.5 \mathrm{~kg}$ have been recruited to date. There were no changes in heart rate throughout the study. Blood pressure increased significantly during the first 3 minutes $(\mathrm{P}<0.05)$ with no further increase over the course of the study. End-tidal $\mathrm{CO}_{2}$ increased at every interval throughout the study period $(\mathrm{P}<0.05)$ until pneumoperitoneum was discontinued.

DISCUSSION: The main finding in this study was the gradual but continuous increase in $\mathrm{ETCO}_{2}$ at each interval over the course of 20 minutes, despite a plateau effect of blood pressure within the first 3 minutes of pneumoperitoneum. This would suggest that retroperitoneal laparoscopy is associated with a slow but continuous diffusion of $\mathrm{CO}_{2}$ through tissues in children.

\section{REFERENCES:}

1. J Uro l160:1138-41.

2. Asso cAn asth ofGB an dIrelan dabstract, 2001 